\title{
ДИСКУССИИ
}

\section{Технологические платформы как коммуникационный инструмент реализации финансового потенциала развития российской экономики}

\author{
Владимирова O.H. ${ }^{14}$, Дягель O.Ю..$^{15}$
}

В статье рассматривается сущиность понятия «технологические платформы», его взаимосвязь с понятием «кластер»; отдельно рассмотрен вопрос их финансирования; приводится сравнительная характеристика подходов $\kappa$ формированию европейских $u$ российских технологических платформ, в том числе с точки зрения привлечения финансовых ресурсов для их функиионирования; выделяются проблемы создания технологических платформ.

\section{JEL: $O 32$}

Ключевые слова: инновачионное развитие, технологические платформы, кластеры

Приоритетным направлением повышения эффективности и конкурентоспособности российской экономики является создание и развитие национальных и региональных инновационных систем. Значительная роль в данном процессе отводится формированию национальных приоритетов технологического развития и объединения усилий бизнеса, науки, государства по их реализации. Действенным инструментом решения такой задачи являются технологические платформы, впервые и широко используемые в странах Евросоюза.

Термин «технологические платформы» (European Technology Platform) был введен в 2004 году Еврокомиссией в докладе «Технологические платформы: от определения к общей программе исследований» для обозначения тематических направлений, в рамках которых сформулированы научно-технические приоритеты Евросоюза в части взаимодействия европейских государств, их бизнеса, науки и образования, которые должны решить задачу технологической независимости Европы (Механик, 2011). По обозначенным направлениям осуществляется выделение «существенных объемов финансирования для проведения различных научно-исследовательских работ, непосредственно связанных с их практической реализацией предприятиями малого и среднего бизнеса и промышленности» (Технологические платформы: взаимодействие... 2011).

Опираясь на имеющийся опыт, идея создания технологических платформ в целях содействия инновационному развитию российской экономики предложена (и уже получила свое практическое развитие) Правительством РФ, а именно Министерством экономического развития и Министерством образования и науки. В этой связи вопросы теоретических основ такой системы инновационного развития экономики России требуют на сегодняшний день комплексного изучения. Прежде всего это делает необходимым анализ терминологического статуса понятия «технологическая платформа» с точки зрения его семантики и корреспонденции с другими схожими на первый взгляд понятиями, применяемыми в области исследований закономерностей пространственной экономики.

\footnotetext{
14 Кандидат экономических наук, профессор кафедры «Финансы и кредит» Красноярского государственного торгово-экономического института

15 Кандидат экономических наук, доцент кафедры «Экономический анализ и статистика» Красноярского государственного торгово-экономического института
} 
Понятие «технологическая платформа» относится к числу достаточно многофункциональных с точки зрения возможностей его использования. В частности, его рабочие качества обнаруживаются не только в экономических науках, что свойственно современным публикациям по данной тематике, но изначально - в технических. В последних данное понятие традиционно применяется для характеристики основ каких-либо производственных операций, которые выполняются в строго определенной последовательности.

Современные тенденции и процессы глобализации знаний существенно расширили границы области применения рассматриваемого понятия. Так, согласно Т. Хиндерлингу, понятие технологической платформы представляет собой ансамбль технологий, находящихся в единой области знаний (Hinderling, 2007).

В целом анализ практики применения данного понятия в современных публикациях показывает, что на сегодняшний день термин «технологические платформы» выступает макроэкономической категорией инновационного менеджмента.

Таблица 1

Макроэкономическое содержание понятия «технологические платформы»

\begin{tabular}{|c|c|}
\hline По оп] & По определению Правительства РФ \\
\hline 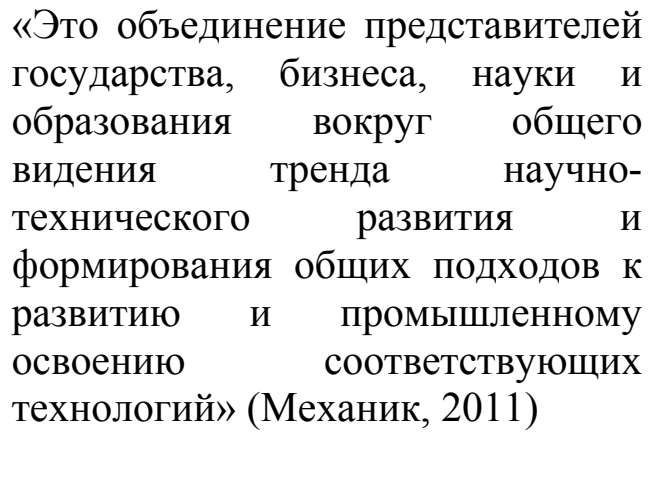 & $\begin{array}{l}\text { «Коммуникационный инструмент, направленный на } \\
\text { активизацию усилий по созданию перспективных } \\
\text { коммерческих технологий, новых продуктов (услуг), } \\
\text { на привлечение дополнительных ресурсов для } \\
\text { проведения исследований и разработок на основе } \\
\text { участия всех заинтересованных сторон (бизнеса, } \\
\text { науки, государства, гражданского общества), } \\
\text { совершенствование нормативно-правовой базы в } \\
\text { области научно-технологического, инновационного } \\
\text { развития...» (Порядок формирования перечня... 2010) }\end{array}$ \\
\hline
\end{tabular}

Приведенные в таблице 1 сложившиеся современные дефиниции термина «технологические платформы» позволяют утверждать, что содержательно - это объект инновационной инфраструктуры, который позволяет обеспечить интеграцию государства, науки и бизнеса для объединения и концентрации необходимых ресурсов на приоритетных направлениях научно-технологического развития страны.

Глубокому пониманию сущности термина «технологические платформы», с нашей точки зрения, будет способствовать проведение его сопоставления по ряду функциональных параметров и содержательных характеристик с другой широко известной российской экономике формой экономических объединений - кластерами.

С этой целью прежде всего приведем некоторые трактовки понятия «кластер», которые используются в современных экономических источниках.

1. Кластер - это сосредоточение наиболее эффективных и взаимосвязанных видов экономической деятельности, т.е. совокупность успешно конкурирующих фирм, которые образуют «золотое сечение» всей экономической системы государства, обеспечивают конкурентные позиции на отраслевом и национальном, мировом рынках (Тэпман, 2004).

2. Кластеры - «географическое средоточие взаимосвязанных компаний и организаций, относящихся к определенному виду деятельности. Кластеры охватывают область связанных между собой объектов, имеющих важное значение в плане конкурентоспособности. Они включают, например, поставщиков специальных ресурсов (комплектующих, инструментария, слуг) и особых видов инфраструктуры» (Яновская, 2003).

3. Кластер - это «сеть поставщиков, производителей, потребителей, элементов промышленной инфраструктуры, исследовательских институтов, взаимосвязанных в процессе создания добавочной стоимости» (Ялов). В данном аспекте кластер 
рассматривается как синергетический эффект региональной агломерации, т.е. «близости потребителя и производителя, сетевых эффектов, диффузии знаний и умений за счет миграции персонала и выделения бизнеса» (Ялов).

5. Кластер - «индустриальный комплекс, сформированный на базе территориальной концентрации сетей специализированных поставщиков, основных производителей, связанных технологической цепочкой, и выступающих альтернативой секторальному подходу» (Андрианова).

Анализ содержания приведенных выше определений позволяет заключить, что кластеры представляет собой группу географически локализованных взаимосвязанных предприятий, организаций и учреждений, взаимодополняющих друг друга и усиливающих конкурентные преимущества отдельных участников и кластера в целом. В контексте такого понимания данной категории мы разделяем точку зрения тех авторов, которые утверждают, что понятие кластера является более узким, чем понятие технологической платформы в редакции Правительства РФ (см. табл. 1).

В подтверждение авторской позиции в систематизированном виде в таблице 2 проведем сравнительную характеристику рассматриваемых понятий.

Таблица 2

Сравнительный анализ понятий «кластеры» и «технологические платформы» по основным содержательным характеристикам

\begin{tabular}{|c|c|c|}
\hline $\begin{array}{r}\text { Харак } \\
\text { сра }\end{array}$ & Кластеры & Технологические платформы \\
\hline $\begin{array}{l}\text { Ожидаемый } \\
\text { результат }\end{array}$ & $\begin{array}{l}\text { Обеспечивает экономию } \\
\text { счет эффректа масштаба }\end{array}$ & $\begin{array}{lr}\text { Обеспечивает } & \text { эффект } \\
\text { инновационности } & \text { наиболее } \\
\text { перспективных } & \text { направлений } \\
\text { развития экономики } & \end{array}$ \\
\hline $\begin{array}{l}\text { Способ получения } \\
\text { результата }\end{array}$ & $\begin{array}{l}\text { Объединение представителей } \\
\text { как одной, так и paзныхх } \\
\text { отраслей }\end{array}$ & $\begin{array}{l}\text { Объединение усилий государства, } \\
\text { бизнеса и науки в рамках единого } \\
\text { сектора экономики }\end{array}$ \\
\hline $\begin{array}{l}\text { Географическое } \\
\text { расположение }\end{array}$ & $\begin{array}{lr}\text { Построение } & \text { кластеров четко } \\
\text { связано c c } & \text { определенной } \\
\text { территорией } & \end{array}$ & $\begin{array}{lcr}\text { Участники } & \text { не } & \text { обязательно } \\
\text { должны } & \text { иметь } & \text { единое } \\
\text { географическое расположение }\end{array}$ \\
\hline $\begin{array}{l}\text { Технологическая } \\
\text { составляющая }\end{array}$ & 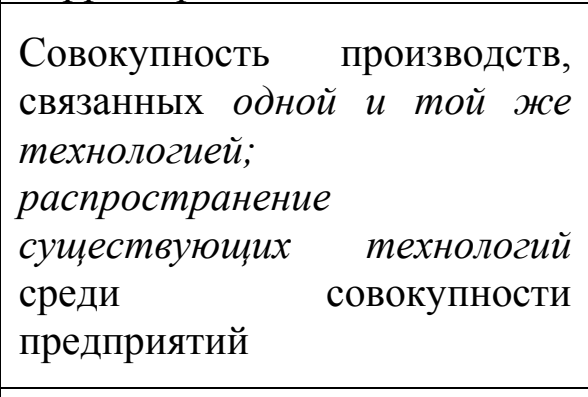 & 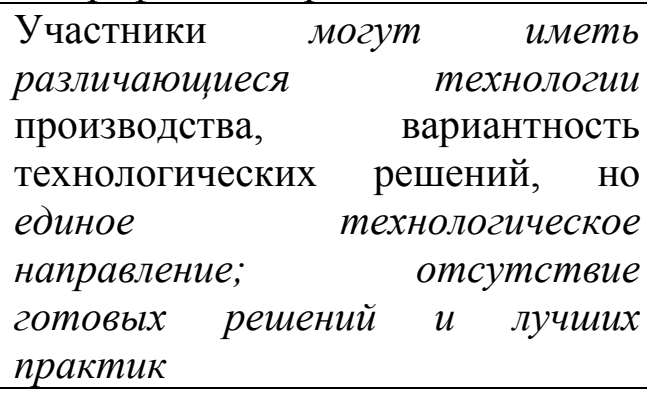 \\
\hline $\begin{array}{l}\text { гность } \\
\text { га }\end{array}$ & $\begin{array}{l}\text { Сосредоточены вокруг одного } \\
\text { центра - лидирующего } \\
\text { крупного предприятия }\end{array}$ & $\begin{array}{l}\text { Равноправное участие, } \\
\text { координируемое иницииатором }\end{array}$ \\
\hline $\begin{array}{l}\text { Степень } \\
\text { государственного } \\
\text { регулирования }\end{array}$ & $\begin{array}{l}\text { Государством жестко не } \\
\text { регламентируются; имеются } \\
\text { объекты инфраструктуры, } \\
\text { финансируемые из средств } \\
\text { господдержки малого бизнеса }\end{array}$ & $\begin{array}{l}\text { Перечень утверждается на уровне } \\
\text { государственной } \\
\text { частичное } \\
\text { финансирование }\end{array}$ \\
\hline $\begin{array}{l}\text { Источник } \\
\text { финансирования }\end{array}$ & \begin{tabular}{lrr} 
Государственное, & \multicolumn{2}{r}{ частное } \\
финансирование (в т.ч. с \\
международным участием)
\end{tabular} & $\begin{array}{l}\text { Государственные, общественные и } \\
\text { частные } \\
\text { финансирования }\end{array}$ \\
\hline
\end{tabular}


При анализе представленной в таблице 2 информации становится ясно: общность кластеров и технологических платформ определяется следующим обстоятельством: значимость их активации и развития для развития экономики заключается в том, что они способствуют интенсификации инновационной активности последней. Наряду с этим краеугольным моментом формирования технологических платформ, в отличие от кластеров, является не просто территориально-географическое сближение, территориально изолированное объединение производств нескольких разных отраслей, между которыми возможны синергия и взаимно функциональные отношения. Принципиально приоритетно здесь доведение ряда новых, научно обоснованных технологий, решений и достижений НТП до новых систем практической деятельности стратегически важных для экономики России отраслей, выбор которых является задачей, решаемой на первом этапе формирования и развития технологических платформ.

Успех создания, функционирования и развития как кластеров, так и технологических платформ, помимо прочего, во многом определяется решением задачи изыскания и концентрации источников их финансирования. В качестве таковых выступают средства государственного финансирования, внебюджетные и частные источники финансирования.

Опираясь на результаты исследований, опубликованные авторами ClusterInitiativesGreenBook, можно констатировать, что финансирование кластеров (в ходе исследования их было опрошено по всему миру более двухсот) в большей части осуществляется за счет средств государства. В частности, на данный источник приходится $54 \%$ от всего объема привлеченных финансовых ресурсов. Остальные источники средств распределились следующим образом: $25 \%$ - совместное финансирование со стороны государства и бизнеса, $18 \%$ - финансирование со стороны только бизнес-сообществ, 2 и 1\% соответственно международные организации и научное сообщество (Sölvell, Lindqvist, Ketels, 2003). Важно отметить, что приоритетная роль государства в финансировании кластера характерна при его создании, что имеет своей целью привлечение предпринимательских структур. В дальнейшем же возрастает долевое участие смешанной формы финансирования.

При решении вопроса финансового обеспечения технологических платформ предполагается приоритетно смешанная форма финансирования. В частности, с организациями - победителями открытых конкурсов на выполнение заказов по осуществлению научно-исследовательских, опытно-конструкторских и опытнотехнологических работ в рамках технологических платформ будут заключаться государственные контракты. Минобрнауки России будет осуществлять их бюджетное финансирование, при котором объем внебюджетного софинансирования должен быть не менее $40 \%$ от общего объема финансирования проекта по выполнению научноисследовательских работ и не менее $50 \%$ - при финансировании проекта по выполнению опытно-конструкторских или опытно-технологических работ. Кроме того, допускается сохранение гибкого подхода в решении данного вопроса, т.е. «финансирование фундаментальных исследований, которые могут быть менее интересны бизнесу» (Технологические платформы: взаимодействие... 2011), приоритетно может осуществлять государство. А бизнес-сообщество будет производить финансовые вложения в технологические проекты или в НИОКРовские работы, которые являются привлекательными для него с позиции возможности их коммерциализации. Практическая реализация данного подхода, который видится более привлекательным относительно имеющейся практики финансирования деятельности кластеров, бесспорно, будет содействовать оптимизации процесса финансирования технологических платформ, что в конечном итоге начнет формировать предпосылки успешного их создания, функционирования и последующего развития.

В проекте Стратегии инновационного развития России до 2020 года указывается, что технологические платформы не рассматриваются в качестве единственного и универсального инструмента обеспечения частно-государственного партнерства в 
инновационной сфере, их формирование оправдано при наличии следующих проблем:

- множественность потенциальных участников технологической платформы и косвенных бенефициаров от ее реализации; необходимость обеспечения обсуждения перспектив технологической модернизации и форм партнерства бизнеса, науки, государства;

- слабая структурированность интересов бизнеса в разработке и внедрении новых технологий, в подготовке кадров; необходимость согласования интересов и определения требований к важнейшим базовым технологиям;

- многодисциплинарность необходимых исследований для разработки перспективных технологий; неясность существующих научно-технологических компетенций, наличие ведомственных барьеров между научными организациями (Инновационная Россия-2020...).

Технологические платформы представляют собой некий механизм, призванный объединить усилия для формирования единой стратегии развития направления с учетом интересов всех сторон. Эффективность таких проектов, работающих на базе партнерских отношений государства, бизнеса и экспертного сообщества, наглядно доказана в странах Евросоюза. Именно поэтому в качестве модели для технологических платформ РФ приводятся Европейские технологические платформы (ЕТП), которые применяются т уже почти десять лет.

Сравнительную оценку зарубежного и российского подхода к формированию технологических платформ можно получить, опираясь на информацию, обобщенную в таблице 3.

Таблица 3

Сравнительная характеристика подходов к созданию технологических платформ в Европе и в Российской Федерации

\begin{tabular}{|c|c|c|}
\hline \multirow[b]{2}{*}{$\begin{array}{l}\text { Параметры } \\
\text { сравнения }\end{array}$} & \multicolumn{2}{|c|}{ Технологические платформы } \\
\hline & $\begin{array}{c}\text { Международная практика } \\
\text { (европейские технологические } \\
\text { платформы) }\end{array}$ & Российская практика \\
\hline $\begin{array}{l}\text { Цель как } \\
\text { коммуникац } \\
\text { ионного } \\
\text { инструмента }\end{array}$ & $\begin{array}{l}\text { - определение у унифицированного } \\
\text { подхода в сочетании основных } \\
\text { экономических, технологических и } \\
\text { социальных вызовов, которые являются } \\
\text { жизненно важными для будущего } \\
\text { европейской конкурентоспособности и } \\
\text { экономического роста }\end{array}$ & $\begin{array}{l}\text { - координация усилий власти, бизнеса и } \\
\text { науки для модернизации экономики }\end{array}$ \\
\hline $\begin{array}{l}\text { Решаемые } \\
\text { задачи }\end{array}$ & 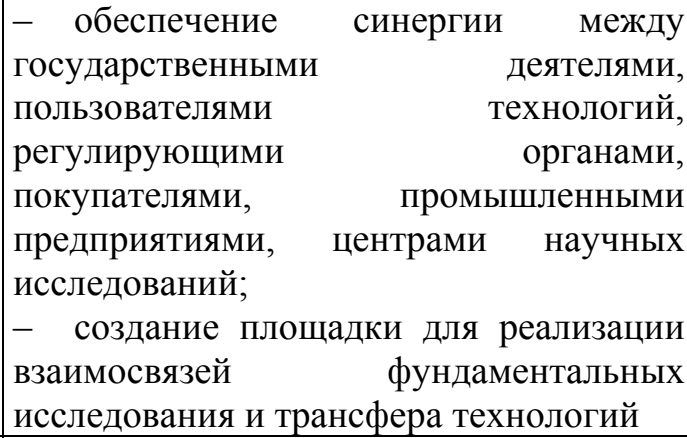 & 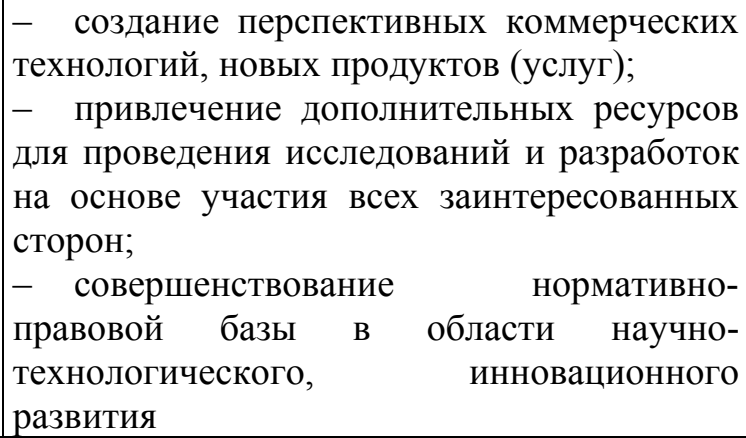 \\
\hline $\begin{array}{l}\text { Роль в } \\
\text { развитии } \\
\text { экономики }\end{array}$ & \begin{tabular}{lrr}
\multicolumn{2}{|c}{ объединяют } & \multicolumn{2}{r}{ основные } \\
заинтересованные & стороны & и \\
обеспечивают диалог & общества \\
бизнеса; & & \\
- & способствуют & направлению \\
инвестиций в & научно-техническое \\
развитие; & \multicolumn{2}{l}{} \\
$-\quad$ мобилизуют & и & направляют \\
существующие возможности в области \\
исследований и разработок, способствуя
\end{tabular} & 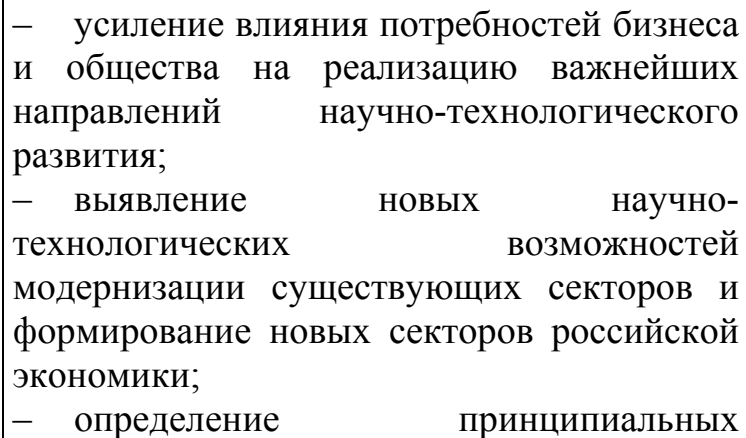 \\
\hline
\end{tabular}




\begin{tabular}{|c|c|c|}
\hline & $\begin{array}{l}\text { более эффективному } \\
\text { инновациям; } \\
-\quad \text { стимулируют } \\
\text { европейской } \quad \text { и } \\
\text { исследовательских программ; } \\
-\quad \text { вносят вклад во всеобщий рост } \\
\text { экономики Евросоюза }\end{array}$ & 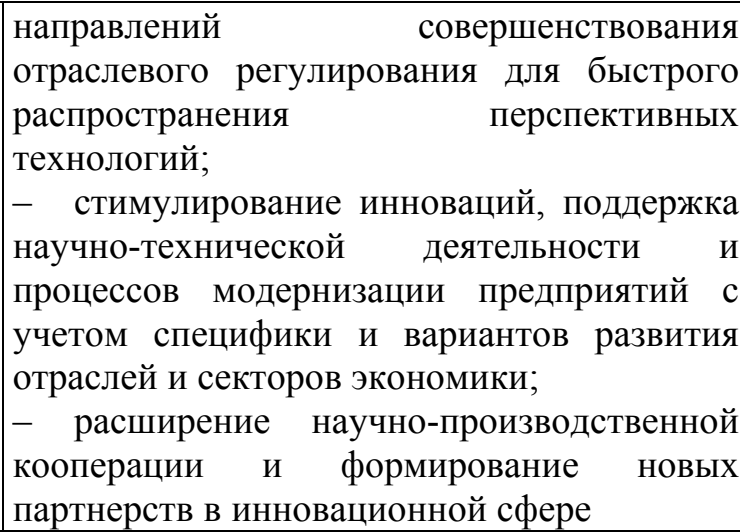 \\
\hline $\begin{array}{l}\text { Задачи } \\
\text { формирован } \\
\text { ия } \\
\text { развития ТП }\end{array}$ & 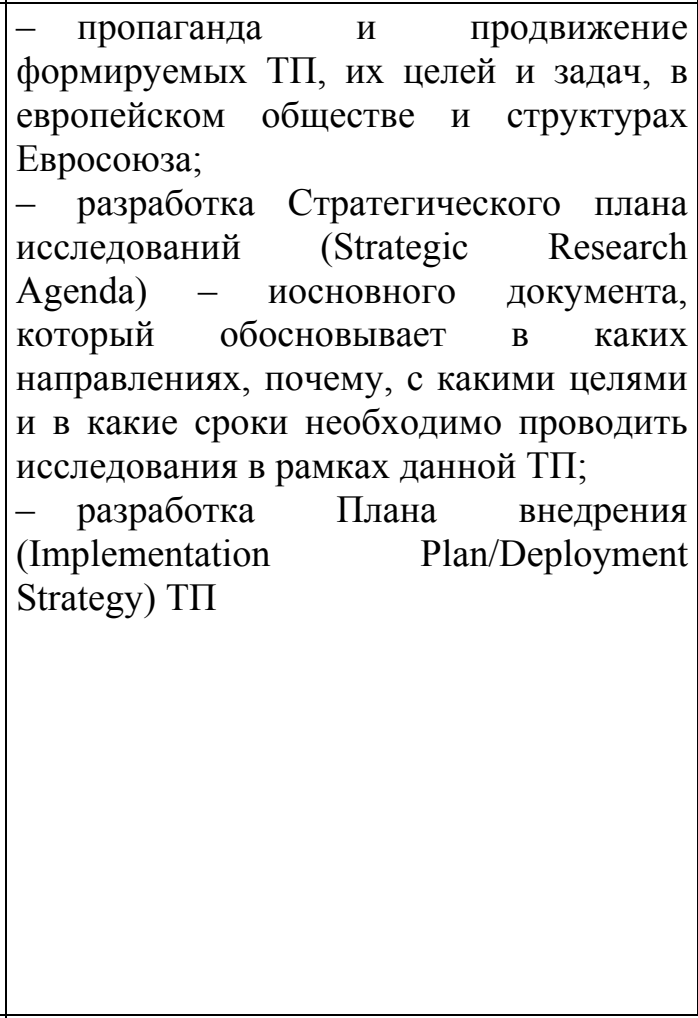 & 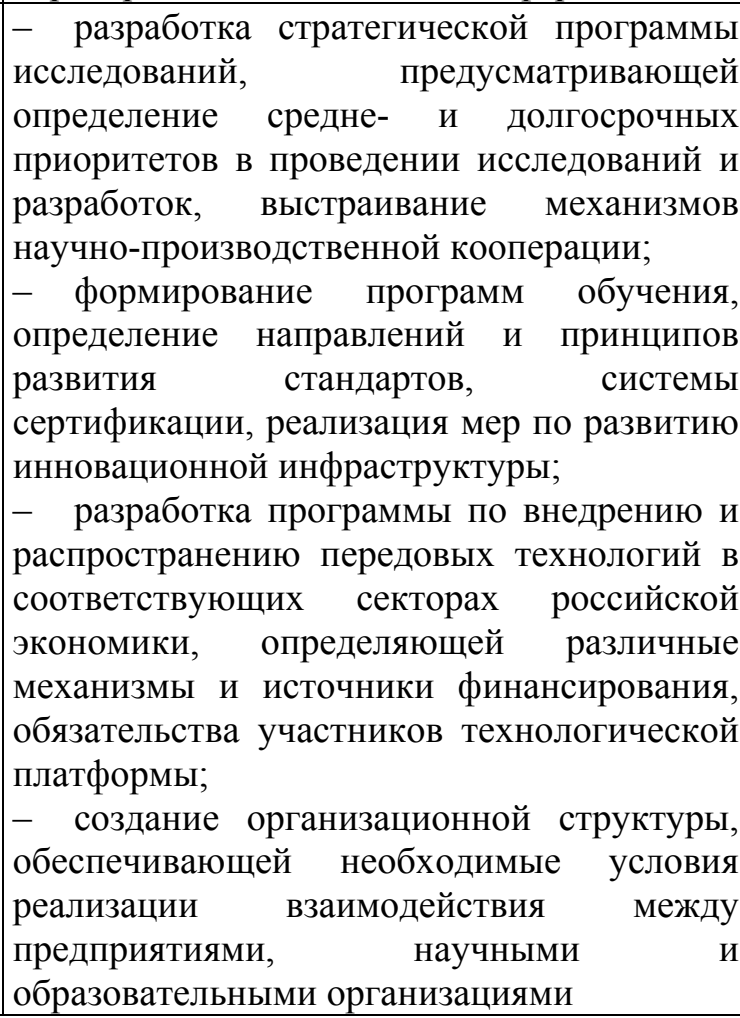 \\
\hline & \multicolumn{2}{|c|}{ 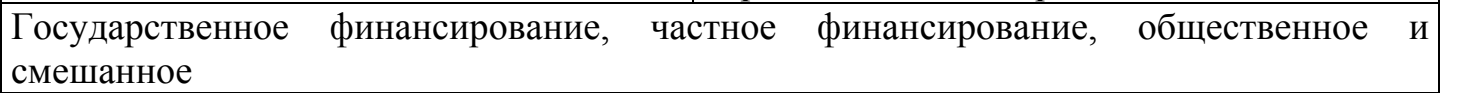 } \\
\hline Інципы & $\begin{array}{l}-\quad \text { открытость для присоединения и } \\
\text { информационная прозрачность; } \\
-\quad \text { повышение осведомленности; } \\
-\quad \text { финансовый инжиниринг; } \\
-\quad \text { индивидуальность организационной } \\
\text { структуры; } \\
-\quad \text { интернациональность }\end{array}$ & 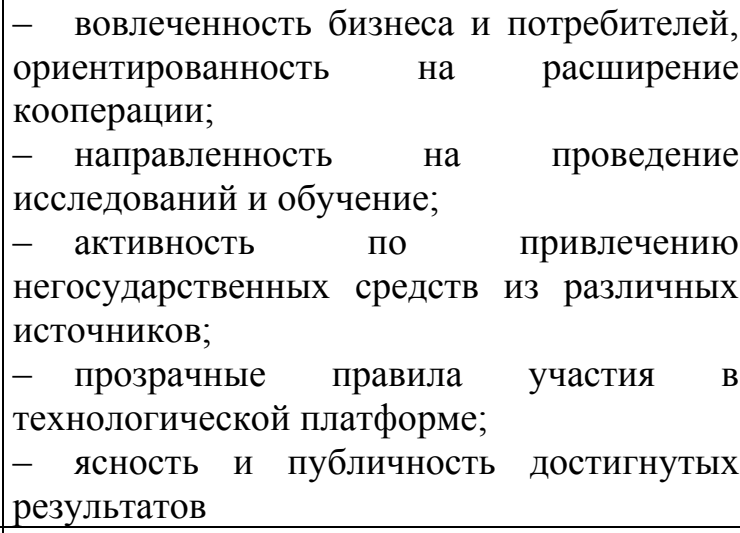 \\
\hline Участники & $\begin{array}{l}-\quad \text { регулирующие структуры; } \\
-\quad \text { промышленность; } \\
-\quad \text { государственные структуры; } \\
-\quad \text { исследовательские институты } \\
\text { академическое сообщество; } \\
-\quad \text { финансовые структуры; } \\
-\quad \text { гражданское общество }\end{array}$ & 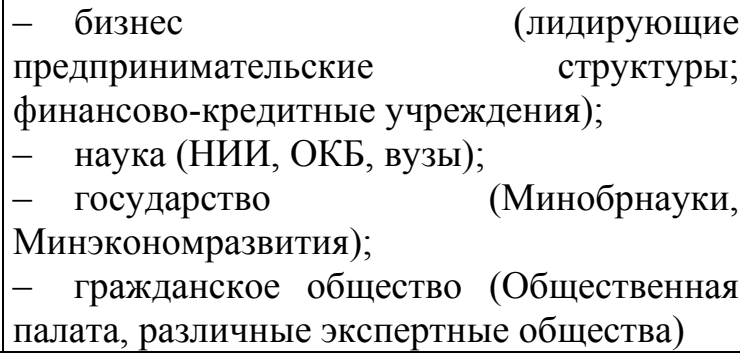 \\
\hline
\end{tabular}




\begin{tabular}{|c|c|c|}
\hline Роль власти & $\begin{array}{l}-\quad \text { продвижение концепции ЕТП; } \\
-\quad \text { ограниченная } \\
\text { поддержка; } \\
-\quad \text { отсутствие } \quad \text { рычагов } \\
\text { деятельности каких-либо платфонм }\end{array}$ & $\begin{array}{l}\text { - прямое у участие представителей } \\
\text { государства в органах } \\
\text { реализацией платформы; } \\
\text { - проведение обсуждения и экспертизы } \\
\text { отдельных готовящихся решений в рамках } \\
\text { технологической платформы; } \\
\text { - рассмотрение и учет при принятии } \\
\text { решений предложений со стороны } \\
\text { участников технологической платформы по } \\
\text { совершенствованию } \\
\text { регулирования; } \\
- \text { мониторинг на государственном уровне } \\
\text { прогресса в достижении целей и задач } \\
\text { технологической платформы }\end{array}$ \\
\hline $\begin{array}{l}\text { Количество } \\
\text { ТП }\end{array}$ & 38 утвержденных & 27 утвержденных и 1 рекомендованная \\
\hline $\begin{array}{l}\text { Распределен } \\
\text { ие по } \\
\text { отраслям }\end{array}$ & \begin{tabular}{|l}
$-\quad$ энергетические технологии (8); \\
$-\quad$ информационно-коммуникационные \\
технологии (6); \\
$-\quad$ технологии транспорта (4); \\
$-\quad$ многоотраслевые (4); \\
$-\quad$ медицина и ветеринария (3); \\
$-\quad$ сельское хозяйство и производство \\
продуктов питания (3); \\
$-\quad$ электроника (2); \\
$-\quad$ космические технологии (1); \\
$-\quad$ черная металлургия (1); \\
$-\quad$ химическая промышленность (1); \\
$-\quad$ строительство (1); \\
$-\quad$ добыча и переработка минеральных \\
ресурсов (1); \\
$-\quad$ лесная и деревообрабатывающая \\
промышленность (1); \\
$-\quad$ водоснабжение и санитария (1); \\
$-\quad$ текстильная промышленность (1)
\end{tabular} & $\begin{array}{l}-\quad \text { энергетика (4); } \\
- \text { авиакосмические технологии (3); } \\
- \text { медицина и биотехнологии, включая } \\
\text { промышленные биотехнологии } \\
\text { фармацевтику (3); } \\
-\quad \text { ядерные и радиационные технологии } \\
\text { (3); } \\
-\quad \text { добыча природных ресурсов } \\
\text { нефтепереработка (3); } \\
-\quad \text { электроника и машиностроение (3); } \\
-\quad \text { информационно-коммуникационные } \\
\text { технологии (2); } \\
-\quad \text { фотоника (лазерные технологии и } \\
\text { производство светодиодов) (2); } \\
-\quad \text { технологии транспорта (2); } \\
-\quad \text { технологии металлургии и новые } \\
\text { материалы (2); } \\
-\quad \text { технологии экологического развития (1 } \\
\text { рекомендованная). }\end{array}$ \\
\hline $\begin{array}{l}\text { Фактически } \\
\text { й подход к } \\
\text { процессу } \\
\text { формирован } \\
\text { ия }\end{array}$ & $\begin{array}{l}\text { принцип «снизу - вверх» («bottom-up» } \\
\text { process) }\end{array}$ & $\begin{array}{l}\text { на федеральном уровне по принципу } \\
\text { «сверху-вниз» }\end{array}$ \\
\hline $\begin{array}{l}\text { Связи в } \\
\text { модели } \\
\text { построения }\end{array}$ & \multicolumn{2}{|c|}{ Горизонтальные, вертикально ориентированные, секторальные } \\
\hline
\end{tabular}

Источник: (Лукша, 2010; О формировании технологических платформ... 2009; Перечень технологических платформ... 2011; Порядок формирования перечня... 2010; Пономарев, 2011; Технологические платформы и инновационная активность, 2012)

Анализ представленного материала показывает, что реализуемые в Евросоюзе и в Российской Федерации подходы к созданию технологических платформ коррелируют между собой по сущностному содержанию целей, роли, по составу источников привлечения финансового капитала, по большей части принципов, по составу участников, а также по направлениям формирования. Однако, по мнению бывшего заместителя министра образования и науки РФ А.Пономарева, российские технологические платформы «направлены, в первую очередь, на поиск новых научно-технических возможностей модернизации существующих и формирования новых секторов российской экономики, на расширение научно-производственной кооперации и создание новых партнерств в 
инновационной сфере» (Пономарев, 2011).

С нашей точки зрения, существенное различие возникает в распределении количества созданных технологических платформ по отраслям (некое единство прослеживается лишь в приоритетности их создания в энергетике), в самом их количестве (это объясняется исключительно начальной стадией данного процесса в экономике России), но главное - в фактически состоявшемся подходе к созданию технологических платформ. Последнее проявляется в том, что в России инициирование технологических платформ проходило по принципу «сверху - вниз» (Технологически платформы и...). Следствием этого явилась некая их «территориальная концентрация», что провоцирует угрозу их содержательной трансформации в кластеры. В частности, как показывает анализ региональной принадлежности организаций, являющихся координаторами 27 технологических платформ, их распределение по территории РФ является достаточно ограниченным. Так, из общей их совокупности по 19 платформам (или 70,4\% от общей их совокупности) организациикоординаторы расположены в Москве.

Такая региональная структура организаций-координаторов технологических платформ отражает их привязку преимущественно к ЦФО и в существенно меньшей степени - к СФО и СЗФО, что характеризует доминантную роль отдельного региона в реализации инновационной политики государства. Безусловно, это может явиться причиной снижения эффективности работы рассматриваемого инструмента активизации инновационного развития экономики страны.

В данном случае следует согласиться с мнением отдельных специалистов о том, что более «результативным представляется принцип формирования заявок на создание технологических платформ «снизу - вверх», когда инициативы исходят из регионов в федеральный центр» (Технологически платформы и...). Именно такой подход реализуется при создании технологических платформ в Евросоюзе и он уже доказал свою действенность и состоятельность.

Существует, на наш взгляд, и ряд других проблем в российской практике формирования и реализации технологических платформ. Среди них (перечень не исчерпывающий):

- сохраняющаяся в целом неясность с процедурой контроля в последующие годы, а также с критериями и показателями эффективности их работы;

- необходимость дальнейшей разработки инструментов функционирования и поддержки технологических платформ;

- координация взаимодействия участников технологических платформ и межбюджетных региональных взаимоотношений;

- финансирование организационных этапов создания технологических платформ.

Решение указанных проблем лежит в основе обеспечения результативности содействия технологических платформ инновационному развитию экономики России, что в свою очередь требует активизации научных исследований, ориентированных на создание теоретических, методологических и методических положений по развитию данного вопроса.

\section{Список литературы}

1. Андрианова А.Ю. Кластеры как инструмент развития некоммерческих организаций / А.Ю.Андрианову, Л.Ланцен. URL: http://journal.vlsu.ru (дата обращения: 04.02.2012).

2. Инновационная Россия - 2020 (Стратегия инновационного развития Российской Федерации на период до 2020 года). Проект Минэкономразвития. URL: http://www.economy.gov.ru/minec/activity/ sections/innovations/doc20101231 016 (дата обращения: 10.10.2011).

3. Лукша Лукша О.П. Европейские технологические платформы: возможности использования европейского опыта для создания нового инструмента содействия инновационному развитию российской экономики // Инновации. 2010. № 9 (143). С. 
34-41.

4. Механик А. Кто поедет на платформе // Эксперт. 2011. № 35 (768). URL: http://expert.ru/expert/2011/35/kto-poedet-na-platforme/?n=87778 (дата обращения: 04.02.2012).

5. О формировании технологических платформ: доклад директора Департамента стратегического управления (программ) и бюджетирования A.E. Шадрина. URL: http://www.economy.gov.ru/minec/about/structure/depstrategy/doc20111122 09 обращения: 04.02.2012).

6. Перечень технологических платформ: решение Правительственной комиссии по высоким технологиям и инновациям от 1 апреля 2011 г., протокол № 2. URL: http://www.economy.gov.ru/minec/activity/sections/innovations/formation/doc20110610_0 14 (дата обращения: 04.02.2012).

7. Технологические платформы: взаимодействие бизнеса и науки // Ректор вуза. № 5. 2011. С. 56-59.

8. Порядок формирования перечня технологических платформ: решение Правительственной комиссии по высоким технологиям и инновациям от 3 августа 2010 г., $\quad$ протокол № 4 URL: http://www.strf.ru/material.aspx?CatalogId=37188\&d no=37192 (дата обращения: 04.02.2012).

9. Пономарев А. Не слепок, но похоже // Поиск. 2011. № 4. С. 6.

10. Портер М. Конкуренция. М.: Вильямс, 2003.

11. Технологические платформы и инновационная активность // Капитал страны: федеральное интернет-издание. URL: http://www.kapitalrus.ru/index.php/articles/article/200944 (дата обращения: 04.02.2012).

12. Тэпман Л.Н. Предпринимательское управление. Зарубежный опыт. М., 2004.

13. Яновская Ю. Кластеры. Что это такое ? // Власть. 2003. № 3. С. 73-76.

14. Ялов Д.А. Кластерный подход как технология управления региональным экономическим развитием. URL: http:// subcontract.b (дата обращения: 04.02.2012).

15. Sölvell, Ö., Lindqvist, G., Ketels, C. (2003), The Cluster Initiative Greenbook, URL: $\mathrm{http}: / / \mathrm{www}$.cluster-research.org.

16. Hinderling, T. (2007), Wozu offene Technologieplattform, Volkswirtschaft,10 (2007) 1617. 